\title{
Correction to: Metagenome to phenome approach enables isolation and genomics characterization of Kalamiella piersonii gen. nov., sp. nov. from the International Space Station
}

\author{
Nitin Kumar Singh ${ }^{1} \cdot$ Jason M. Wood ${ }^{1} \cdot$ Snehit S. Mhatre ${ }^{1} \cdot$ Kasthuri Venkateswaran $^{1}$ (D) \\ Published online: 13 July 2019 \\ (C) Springer-Verlag GmbH Germany, part of Springer Nature 2019
}

\section{Correction to: Applied Microbiology and Biotechnology (2019) 103:4483-4497 https://doi.org/10.1007/s00253-019-09813-z}

In our original published manuscript entitled "Metagenome to phenome approach enables isolation and genomics characterization of Kalamiella piersonii gen. nov., sp. nov. from the International Space Station" (Singh et al. 2019), we found a taxonomic description format error: As per the Rule 27 of the ICNP, protologue of the genus is to be provided separate from the species. This is required for the validation of the novel genus and species. The text in the manuscript should be as follow:

\section{DESCRIPTIONS}

\section{Description of Kalamiella gen. nov.}

Kalamiella (N.L. fem. dim. n. Kalamiella, named after APJ Abdul Kalam (1934-2015), a well-known scientist who advanced space research in India)

Cells are Gram-strain-negative, aerobic, motile short rods, occurring in the single or dual arrangement. Colonies are circular, convex with a diameter of approximately $0.6-1.0 \mathrm{~mm}$ and beige in color after $24 \mathrm{~h}$ of incubation on TSA medium at $30^{\circ} \mathrm{C}$. Cell growth occurs at 12 to $37^{\circ} \mathrm{C}$. The $\mathrm{pH}$ tolerance is between 6.0 and 10.0. and shows positive growth at $0-5 \% \mathrm{NaCl}$. Major

The online version of the original article can be found at https://doi.org/ 10.1007/s00253-019-09813-z

Kasthuri Venkateswaran

kjvenkat@jpl.nasa.gov

1 Jet Propulsion Laboratory Biotechnology and Planetary Protection Group, California Institute of Technology, M/S 89-2 4800 Oak Grove Dr., Pasadena, CA 91109, USA cellular fatty acids $(>10 \%)$ are C16:0, C17:0 cyclo, Summed Feature 3 and Summed Feature 8. The DNA G+C content is $57.07 \mathrm{~mol} \%$. Type species is Kalamiella piersonii.

\section{Description of Kalamiella piersonii sp. nov}

Kalamiella piersonii (pierson.i.i N.L gen. n. piersonii referring to Duane Pierson, an accomplished American space microbiologist.)

Has the following characteristics in addition to those given for the genus. Cells are Gram-strain-negative, aerobic, motile short rods (1-1.2 x 2.8 um), occurring in the single or dual arrangement. Colonies are circular, convex with a diameter of approximately $0.6-1.0 \mathrm{~mm}$ and beige in color after $24 \mathrm{~h}$ of incubation on TSA medium at $30^{\circ} \mathrm{C}$. Cell growth occurs at 12 and $37^{\circ} \mathrm{C}$ but not at 4 or $44^{\circ} \mathrm{C}$. The optimum growth was observed at $30^{\circ} \mathrm{C}$. The $\mathrm{pH}$ tolerance is between 6.0 and 10.0, with a $\mathrm{pH}$ optimum at 8.0. All of the strains displayed positive growth at $0-5 \% \mathrm{NaCl}$. The strains were positive for carbon source utilization of Dextrin, DMaltose, N-Acetyl-D-Glucosamine, N-Acetyl- $\beta$-DMannosamine, $\alpha$-D-Glucose, D-Mannose, D-Fructose, DGalactose, L-Rhamnose, Inosine, $1 \%$ Sodium Lactate, DMannitol, myo-Inositol, Glycerol, D-Glucose-6-PO4, DFructose-6-PO4, Troleandomycin, Rifamycin SV, Glycyl- LProline, L-Alanine, L-Arginine, L-Aspartic Acid, L-Glutamic Acid, L-Histidine, Lincomycin, Guanidine HCl, Niaproof 4, DGalacturonic Acid, L-Galactonic Acid Lactone, D-Gluconic Acid, D-Glucuronic Acid, Glucuronamide, Mucic Acid, DSaccharic Acid, Vancomycin, Tetrazolium Violet, Tetrazolium Blue, Citric Acid, D-Malic Acid, L-Malic Acid, Lithium Chloride, and $\gamma$-Amino-Butyric Acid. The strains were negative for carbon source utilization of D-Trehalose, D-Cellobiose, Gentiobiose, Sucrose, D-Turanose, Stachyose, D-Raffinose, aD-Lactose, D-Melibiose, b-Methyl-D-Glucoside, D-Salicin, NAcetyl-D-Galactosamine, N-Acetyl Neuraminic Acid, 3-Methyl Glucose, D-Fucose, L-Fucose, Fusidic Acid, D-Serine, D- 
Sorbitol, D-Arabitol, D-Aspartic Acid, D-Serine, Minocycline, Gelatin, L-Pyroglutamic Acid, L-Serine, Pectin, Quinic Acid, pHydroxy-Phenylacetic Acid, Methyl Pyruvate, D-Lactic Acid Methyl Ester, L-Lactic Acid, $\alpha$-Keto-Glutaric Acid, BromoSuccinic Acid, Nalidixic Acid, Potassium Tellurite, Tween 40, $\alpha$-Hydroxy-Butyric Acid, $\beta$-Hydroxy-D,L-Butyric Acid, $\alpha$ Keto-Butyric Acid, Acetoacetic Acid, Propionic Acid, Acetic Acid, Formic Acid, Aztreonam, Sodium Butyrate, and Sodium Bromate. Major cellular fatty acids (>10\%) are C16:0, C17:0 cyclo, Summed Feature 3 and Summed Feature 8. Lesser fatty acids are C12:0, C14:0, C14:0 2-OH, C19:0 cyclo $\omega 8 \mathrm{c}$, and Summed Feature 2.

The type strain, IIIF1SW-P2 ${ }^{\mathrm{T}}$ (=DSM $108198=\mathrm{NRRL}$ B-65522 $2^{\mathrm{T}}$ ), was isolated from the ISS Port panel of the Cupola, which is the observation deck for the crew. The DNA G+C content of the type strain is $57.07 \mathrm{~mol} \%$ (whole genome).

\section{References}

Singh NK, Wood JM, Mhatre SS, Venkateswaran K (2019) Metagenome to phenome approach enables isolation and genomics characterization of Kalamiella piersonii gen. nov., sp. nov. from the International Space Station. Appl Microbiol Biotechnol https://doi.org/10.1007/ s00253-019-09813-z

Publisher's note Springer Nature remains neutral with regard to jurisdictional claims in published maps and institutional affiliations. 